\title{
Monte Carlo vs. Fuzzy Monte Carlo Simulation for Uncertainty and Global Sensitivity Analysis
}

\author{
Young-Jin Kim \\ Division of Architecture, Architectural Engineering and Civil Engineering, Sunmoon University, Asan, \\ Chungnam 336-708, Korea; yjkim9943@sunmoon.ac.kr; Tel.: +82-41-530-8326 \\ Academic Editor: Ali Bahadory-Jahromi \\ Received: 22 February 2017; Accepted: 29 March 2017; Published: 31 March 2017
}

\begin{abstract}
Monte Carlo simulation (MCS) has been widely used for the uncertainty propagations of building simulation tools. In general, most unknown inputs for the MCS are regarded as single probability distributions based on experts' subjective judgements and assumptions, when simulation information and measured data are inaccurate and insufficient. However, this can lead to meaningless and untrustworthy results, since the results are obtained using only single probability distributions without considering reducible possibilities of some unknown inputs. This paper introduces a fuzzy MCS for dealing with the aforementioned problems. In comparison with the MCS, the fuzzy MCS has the advantage of considering the aleatory and epistemic uncertainty, and can provide a family of probability distributions. This paper also discusses how fuzzy MCS could be effectively used for uncertainty and global sensitivity analysis.
\end{abstract}

Keywords: Monte Carlo simulation; fuzzy Monte Carlo simulation; uncertainty; sensitivity; building simulation

\section{Introduction}

Building performance simulation (BPS) tools, which transform physical phenomena in real systems into mathematical equations in a building simulation domain, generate model risks caused by inherent uncertainty sources. To draw upon the uncertainty sources in the BPS tools, techniques used for the uncertainty propagation are as follows: direct evaluation for linearly parameterized methods; Monte Carlo simulation (MCS) using sampling methods; perturbation methods using first-order or second-order Taylor series expansion; and spectral representations [1]. In particular, the MCS has been recognized as the most dominant approach in the area of building performance simulation because it is easy to use. The uncertainty propagation for the first-principles-based BPS tools includes complex nonlinear models and needs to deal with correlated or high-dimensional inputs; nevertheless, it can provide probabilistic outputs with high performance qualities in spite of the vast computational burdens. Burhenne et al. [2] showed a multi-criteria decision-making methodology (cost and benefit) using the MCS-based uncertainty quantification as a robust design support tool. They indicated that the stochastic multi-criteria decision-making design process should offer more significant insights than the deterministic process. Almeida et al. [3] performed the MCS and life cycle cost (LCC) analysis for a school building energy conservation project. They insisted on the necessity of uncertainty and sensitivity analysis in terms of the effective renovation investment during a building life cycle. Cheng et al. [4] proposed a stochastic approach using the MCS and Markov model for a robust optimal design of chilled water systems.

The two types of uncertainty sources are (1) aleatory uncertainty (i.e., irreducible uncertainty) and (2) epistemic uncertainty (i.e., reducible uncertainty) [1]. The aleatory uncertainty that cannot be reduced by additional information or data includes nonphysical model inputs with random 
variability [1]. In contrast, the epistemic uncertainty incurred from inaccurate and insufficient information can be significantly reduced if trustworthy information is available. However, the general MCS was propagated using single probability distributions without regard for the reducible possibility embedded in the epistemic uncertainty. In other words, the MCS has a treated limitation on the condition that a priori probability distributions of all unknown inputs are definitely identified as single probability distributions.

This study discusses a fuzzy MCS that can reflect two uncertainty sources (aleatory and epistemic). The fuzzy MCS combines a probability theory of MCS with a possibility theory of fuzzy arithmetic and can acquire a probabilistic output with a family of probability distributions, rather than a single probability distribution. The family of probability distributions can represent the model risks as a range between plausibility (lower limit) and belief (upper limit) [5,6]. The goal of this study is to compare the MCS to the fuzzy MCS with the aim of finding influential design options. For this study, an existing office building is selected and modeled using EnergyPlus 8.0. For this study, uncertainty and global sensitivity analyses were implemented using a Gaussian process (GP) emulator to alleviate the computational burdens of the uncertainty propagation. The GP emulator can be regarded as a surrogate model of a BPS tool with a high-fidelity model such as ESP-r, EnergyPlus, and TRNSYS $[7,8]$.

\section{Uncertainty Sources}

The uncertainties of the BPS tools mainly arise from a lack of definite physical or experimental knowledge (e.g., thermal properties) incurred from inaccurate and insufficient information and random variability (e.g., weather data, occupants' behaviors). In such an uncertain simulation environment, it is impossible to build an ideal model with flawless processes. However, even an imperfect model could be an effective guide for decision support if appropriate uncertainty management is applied. For example, stochastic results using the MCS indicate the limitations of current modelling levels. In addition, risk-based design support tools can identify a best option from vast simulation design spaces, even if it is not an optimal solution in reality.

BPS tools can obtain predicted outputs $(y)$ using idealized mathematical models $\left(\eta\left(\theta_{m}, X\right)\right)$ and model errors $\left(\delta\left(\theta_{m}, X\right)\right)$ composed of various inputs $(X)$ and parameters $\left(\theta_{m}\right)$, as shown in Equation (1). The real behaviors $\left(y_{D}\right)$ can then be obtained using the predicted outputs $(y)$ as well as the sensor errors $\left(\varepsilon\left(x_{D}\right)\right)$ of measured data $\left(x_{D}\right)$, as shown in Equation (2). In other words, the BPS tools will be able to acquire trustworthy results if the simulation experts continue to attempt to reduce the uncertainties inherited in the idealized mathematical models, model errors, and sensor errors. Among these, the model and sensor errors might be able to reduce some of the uncertainties due to advances in computing power, numerical methods, sensor devices, and sensor networks. In this sense, it is important to handle the uncertainties in the idealized mathematical models (i.e., model uncertainty).

$$
\begin{gathered}
y=\eta\left(\theta_{m}, X\right)+\delta\left(\theta_{m}, X\right) \\
y_{D}=y+\varepsilon\left(x_{D}\right)
\end{gathered}
$$

Model uncertainties can be categorized as aleatory or epistemic uncertainties based on the degree to which they were caused by random variability or lack of knowledge, respectively. However, it is difficult to clearly distinguish between an aleatory and epistemic uncertainty due to relative gaps of knowledge and the different physical or experimental capacities of each simulation user [5,6,9]. Nevertheless, Kiureghian [9] insisted that "distinction between aleatory and epistemic is useful for identifying sources of uncertainty that can be reduced, and in developing sound risk and reliability models".

However, most uncertainty studies, reported in a recent building simulation conference [10], focused mainly on predictions based on the probabilistic framework considering only aleatory uncertainty. When considering only aleatory uncertainty, all unknown inputs can be regarded as 
single, a priori, probability distributions, and the predictions propagated by uncertainty techniques (e.g., MCS) are represented as a single probability distribution. It would then be important to determine whether or not a risk-based design with the single probability distribution is unbiased. However, most simulation users might know that some of the unknown inputs cannot be regarded as single, a priori, probability distributions due to epistemic uncertainties. In other words, it is necessary to implement a joint propagation method for two uncertainty sources (aleatory and epistemic). To address the aforementioned issue, this study introduces a fuzzy MCS for the joint propagation method.

\section{Fuzzy Monte Carlo Simulation}

The fuzzy MCS is a joint propagation method based on both the probability theory of MCS and the possibility theory of fuzzy arithmetic. Fuzzy set theory introduced by Zadeh [11] is an effective approach for representing epistemic uncertainty under imperfect knowledge. In the fuzzy set theory, fuzzy numbers are defined as convex and normalized fuzzy sets over the universal set with their fuzzy set membership functions that can be represented as a degree of likelihood between 0 and 1 [5,6,12-15]. In general, the triangular fuzzy number (TFN) has been widely used (Figure 1). A membership function of the fuzzy set $\mathrm{A}$ is represented as $\mu_{A}(x) \in[0,1]$. Using a fuzzy $a$-cut technique of the transformation method [9], a fuzzy interval assigns degrees of likelihood (possibility) to intervals of values using presumption level (a). In other words, the unknown inputs with different types of epistemic uncertainty are transformed into a crisp set representing minimum-maximum intervals using the fuzzy set membership function and the fuzzy $a$-cut technique. For example, if the presumption level (a) is set to 0.5 , the crisp set of the fuzzy $a$-cut $A_{a}=\{x \mid \mu(x) \geq a\}$ with the degree of possibility higher than the presumption level can be represented as [5,10], as shown in Figure 1. To implement the fuzzy MCS, an interval propagation can be performed using an optimization algorithm at the sampling case in the uncertainty propagation. The optimization is used for finding a set of optimal values (presumption level) minimizing or maximizing the given object function (MIN F(X) or MAX $F(X)$ ) subjected to the minimum-maximum intervals. Then, the uncertainty quantifications propagated using the obtained optimal values are represented as a plausibility distribution and a belief distribution.

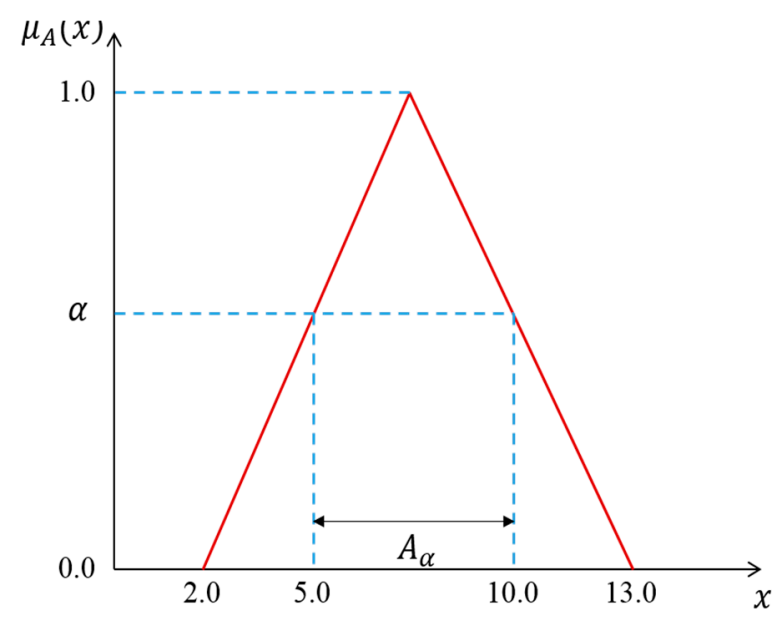

Figure 1. Fuzzy set using triangular fuzzy number.

Figure 2 shows a fuzzy MCS process considering aleatory and epistemic uncertainty. The selected unknown inputs in the model need to be divided into probability distributions that have an aleatory nature or possibility distributions that have an epistemic nature. Probability distributions are propagated using the sampling methods—e.g., Latin hypercube sampling (LHS)—while possibility distributions are represented as minimum-maximum intervals using the random fuzzy $a$-cut technique. In addition, the optimization process is performed to estimate the presumption level (a). With the 
simulation cases and min-max values generated by sampling methods and the estimated presumption levels, a family of probability distributions is calculated.

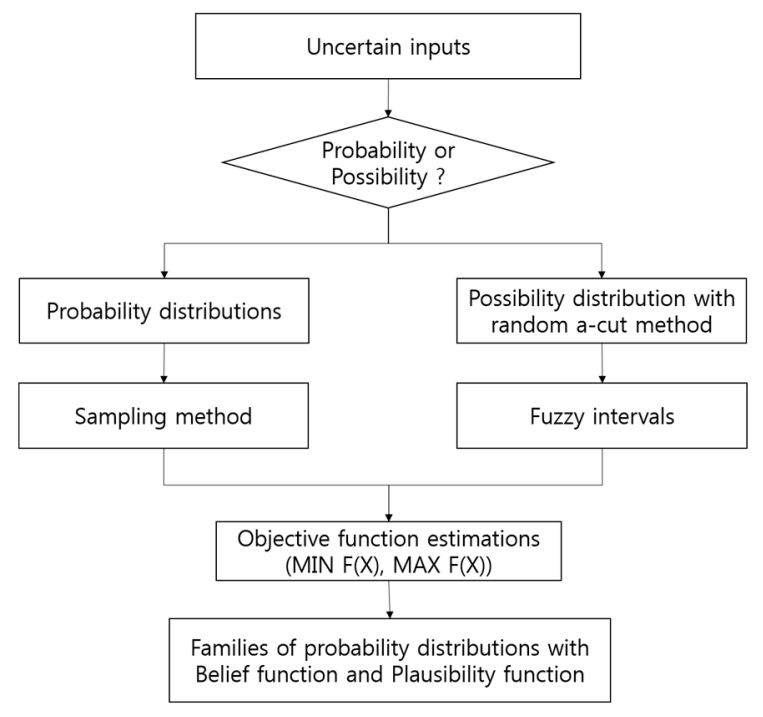

Figure 2. Fuzzy Monte Carlo simulation (MCS) process considering aleatory and epistemic uncertainty.

\section{Target Building and Unknown Inputs}

An office building located in South Korea was chosen and modelled using EnergyPlus 8.0 (Figure 3). The EnergyPlus model using Bayesian calibration was calibrated and validated [16]. With the previous calibrated and validated EnergyPlus model, this study only focuses on the uncertainty analysis and global sensitivity analysis using the MCS or fuzzy MCS.

Table 1 shows the probability distributions and preferred representations (probability or possibility) regarding the design variables. The systems of the design variables were divided into thermal zones, heating, ventilation and air conditioning (HVAC) systems, fans, pumps, and plants, respectively. In addition, the predicted outputs were heating/cooling load, HVAC system load, fan electricity energy consumption, pump electricity energy consumption, and gas energy consumption, respectively. The reason is because the uncertainty and sensitivity results might be biased if it is only performed toward the gas energy consumption with all possible design variables [16]. In the thermal zones, the type and thickness of insulation and type of glass were selected as probability distributions that have an aleatory nature because the type and thickness of the materials (insulation and glass) derived from specific information of the related companies are less likely to reduce the uncertainties in comparison with the other unknown inputs that have an epistemic nature. The indoor loads were regarded as an important target for the future design, since the relocation of the interior space and changes in the highly efficient lighting fixtures and low energy devices can significantly affect the heating/cooling loads. In addition, the indoor set-point temperature was regarded as an adjustable option within the ranges defined in the previous literature [17]. In the given building, the indoor set-point temperatures were set to $20^{\circ} \mathrm{C}$ for heating and $26{ }^{\circ} \mathrm{C}$ for cooling. The design inlet/outlet temperatures and design flow rates for the HVAC systems are adjustable options. Moreover, the design pressure head and motor efficiency for pumps and fans were chosen as the design variables. Finally, the coefficient of performance (COP) of the Absorption Chiller/Heater and the design inlet/outlet temperatures for the plant were chosen as important design variables. In particular, the COP is the thermal efficiency of the equipment system that converts the gas or electric energy into potential and kinetic energy. As the COP increases, the amount of gas or electric energy required to enhance the system efficiency is reduced. 


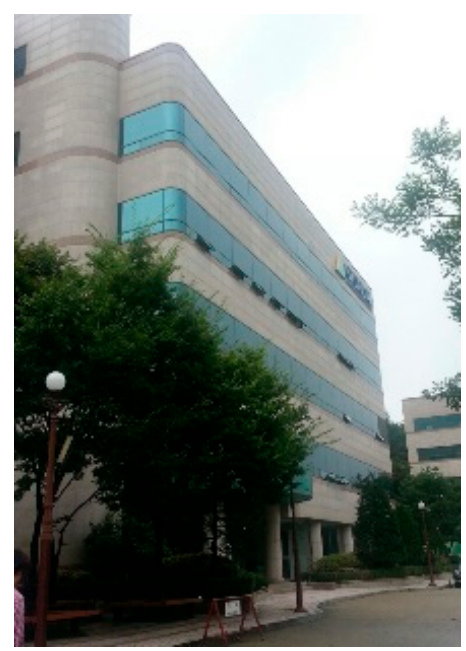

(a)

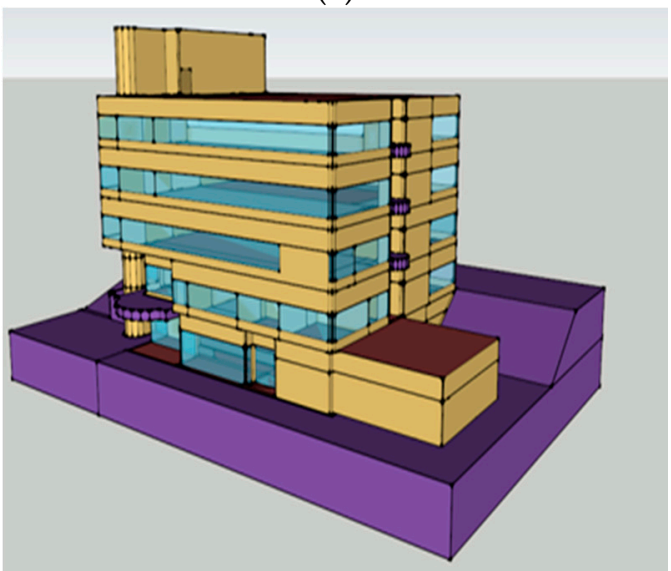

(b)

Figure 3. Target building and simulation model. (a) Real building; (b) EnergyPlus.

Table 1. Unknown inputs.

\begin{tabular}{|c|c|c|c|c|c|}
\hline No. & & Systems & Design Variables & Probability Distributions & $\begin{array}{c}\text { Preferred } \\
\text { Representations }\end{array}$ \\
\hline $\begin{array}{l}x 1 \\
x 2\end{array}$ & \multirow{4}{*}{ Zone } & Insulation & $\begin{array}{l}\text { Type } \\
\text { Thickness }\end{array}$ & $\begin{array}{c}\text { Discrete U }[1,20] \\
\text { Continuous U }[0.005,0.01]\end{array}$ & $\begin{array}{l}\text { Probability } \\
\text { Probability }\end{array}$ \\
\hline $\begin{array}{l}x 3 \\
x 4\end{array}$ & & Glass & $\begin{array}{c}\text { Type } \\
\text { Airtightness ratio }\end{array}$ & $\begin{array}{l}\text { Discrete U }[1,16] \\
\mathrm{T}[0.5,0.8,1.0]\end{array}$ & $\begin{array}{l}\text { Probability } \\
\text { Possibility }\end{array}$ \\
\hline $\begin{array}{l}x 5 \\
x 6 \\
x 7\end{array}$ & & Indoor loads & $\begin{array}{l}\text { Fraction person per area } \\
\text { Fraction internal gain for lights } \\
\text { Fraction internal gain for equipment }\end{array}$ & $\begin{array}{l}\text { T }[0.8,0.9,1.0] \\
\text { T }[0.8,0.9,1.0] \\
\text { T }[0.8,0.9,1.0]\end{array}$ & $\begin{array}{l}\text { Possibility } \\
\text { Possibility } \\
\text { Possibility }\end{array}$ \\
\hline $\begin{array}{l}x 8 \\
x 9\end{array}$ & & $\begin{array}{l}\text { Indoor set-point } \\
\text { temperature }\end{array}$ & $\begin{array}{l}\text { Heating set-point temperature } \\
\text { Cooling set-point temperature }\end{array}$ & $\begin{array}{c}\mathrm{T}[20,21.5,23] \\
\mathrm{T}[26,27,28]\end{array}$ & $\begin{array}{l}\text { Possibility } \\
\text { Possibility }\end{array}$ \\
\hline $\begin{array}{l}\mathrm{x} 10 \\
\mathrm{x} 11\end{array}$ & HVAC & Water & $\begin{array}{c}\text { Design water flow ratio } \\
\text { Design water inlet/outlet temperature ratio }\end{array}$ & $\begin{array}{l}\mathrm{T}[0.8,1.0,1.2] \\
\mathrm{T}[0.8,1.0,1.2]\end{array}$ & $\begin{array}{l}\text { Possibility } \\
\text { Possibility }\end{array}$ \\
\hline $\begin{array}{l}x 17 \\
x 18 \\
x 19\end{array}$ & Fan & Return fan & $\begin{array}{l}\text { Fan efficiency ratio } \\
\text { Pressure rise ratio } \\
\text { Motor efficiency ratio }\end{array}$ & $\begin{array}{l}\mathrm{T}[0.8,1.0,1.2] \\
\mathrm{T}[0.8,1.0,1.2] \\
\mathrm{T}[0.8,1.0,1.2]\end{array}$ & $\begin{array}{l}\text { Possibility } \\
\text { Possibility } \\
\text { Possibility }\end{array}$ \\
\hline
\end{tabular}


Table 1. Cont.

\begin{tabular}{|c|c|c|c|c|c|}
\hline No. & & Systems & Design Variables & Probability Distributions & $\begin{array}{c}\text { Preferred } \\
\text { Representations }\end{array}$ \\
\hline$x 20$ & \multirow{3}{*}{ Pump } & Chilled water & Pump head ratio & $\mathrm{T}[0.8,1.0,1.2]$ & Possibility \\
\hline$x 22$ & & \multirow{2}{*}{ Condenser } & Pump head ratio & $\mathrm{T}[0.8,1.0,1.2]$ & Possibility \\
\hline$x 23$ & & & Motor efficiency ratio & $\mathrm{T}[0.8,1.0,1.2]$ & Possibility \\
\hline$x 26$ & \multirow{4}{*}{ Plant } & \multirow{2}{*}{$\mathrm{COP}$} & COP for cooling & $\mathrm{T}[0.8,1.0,1.2]$ & Possibility \\
\hline$x 27$ & & & COP for heating & $\mathrm{T}[0.8,1.0,1.2]$ & Possibility \\
\hline$x 28$ & & \multirow{2}{*}{$\begin{array}{c}\text { Design } \\
\text { temperature }\end{array}$} & Design inlet temperature ratio & $\mathrm{T}[0.8,1.0,1.2]$ & Possibility \\
\hline$x 29$ & & & Design outlet temperature ratio & $\mathrm{T}[0.8,1.0,1.2]$ & Possibility \\
\hline
\end{tabular}

\section{Development and Validation of Gaussian Process Emulator}

A GP emulator, which is regarded as the surrogate model of EnergyPlus, was used to obtain accurate and reliable uncertainty and global sensitivity results with fast computational speed. In this study, five GP emulators (thermal zones, HVAC systems, fans, pumps, and plants) were constructed.

To generate the training dataset, the number of inputs $(p) x_{1: n}=\left\{x_{1}, \ldots, x_{n}\right\}$ for thermal zone, HVAC system, fan, pump, and plant are set as 9, 4, 6, 6, and 4, respectively. The output dataset $y$ includes heating/cooling load, HVAC system load, fan electricity energy consumption, pump electricity energy consumption, and gas energy consumption. The number of samplings for the LHS method was set at 200. A total of 150 training datasets for the GP emulator and 50 training datasets for validation were employed. The Gaussian Process regression model with Gaussian noise using the generated dataset represents a kernel matrix $K\left(x_{i}, x_{j}\right)$ with zero mean function as shown in Equations (3)-(6). The Gaussian noise $\varepsilon_{i}$ is generally expressed as an independent identically distributed (iid) normal distribution. In this study, a squared exponential covariance function $C\left(x_{i}, x_{j}\right)$ in the kernel matrix was used. A maximum a posteriori (MAP) estimator out of the Bayesian inference was used to estimate three hyperparameters (scaling parameter $\sigma_{s e}^{2}$, length scales $l_{1: p}$, and variance of Gaussian noise $v_{t}$ ).

$$
\begin{gathered}
y_{i}=f\left(x_{i}\right)+\varepsilon_{i} \\
\varepsilon_{i} \sim N\left(0, v_{t}\right) \\
K\left(x_{i}, x_{j}^{\prime}\right)=\left[\begin{array}{ccc}
C\left(x_{1}, x_{1}\right) & \ldots & C\left(x_{1}, x_{p}\right) \\
\ldots & \ldots & \ldots \\
C\left(x_{p}, x_{1}\right) & \ldots & C\left(x_{p}, x_{p}\right)
\end{array}\right] \\
f\left(x_{i}\right) \sim g p\left(0, K\left(x_{i}, x_{j}^{\prime}\right)\right.
\end{gathered}
$$

Table 2 shows the difference in the stochastic predicted outputs between EnergyPlus and the GP emulator using the separate validated dataset. The two-sample Kolmogorov-Smirnov (K-S) test was used to find whether or not the populations of the two samples have the same probability distribution. If $p$-value (0.0-1.0) is greater than 0.05 , the populations of the two samples have the same probability distribution. In the results, the two samples have very similar distributions. This means that the outputs of the GP emulator are similar to those of EnergyPlus. In this study, the GP emulator can be used for uncertainty and global sensitivity analysis. 
Table 2. EnergyPlus vs. Gaussian process (GP) emulator using stochastic results and the two-sample Kolmogorov-Smirnov (K-S) test.

\begin{tabular}{cccccc}
\hline \multirow{2}{*}{ Systems } & \multicolumn{2}{c}{ EnergyPlus (kWh) } & \multicolumn{2}{c}{ GP Emulator (kWh) } & \multirow{2}{*}{$\boldsymbol{p}$-Values } \\
\cline { 2 - 5 } & Mean & STDEV & Mean & SD & \\
\hline Zone & 767,414 & 13,369 & 767,436 & 13,325 & 0.789 \\
HVAC & 592,080 & 11,533 & 591,832 & 9568 & 0.117 \\
Fan & 102,834 & 12,150 & 102,834 & 12,150 & 0.258 \\
Pump & 376,135 & 53,641 & 376,150 & 53,603 & 0.979 \\
Plant & 722,908 & 27,363 & 722,908 & 27,364 & 0.282 \\
\hline
\end{tabular}

SD: Standard Deviation.

\section{Monte Carlo Simulation vs. Fuzzy Monte Carlo Simulation}

\subsection{Uncertainty Results}

Figure 4 shows some sampling results propagated using the LHS method. In the results, uncertainty propagations for the plausibility and belief functions of fuzzy MCS were biased in comparison with those of MCS. These biased propagations were caused by reflecting the epistemic uncertainties incurred from inaccurate and insufficient information.

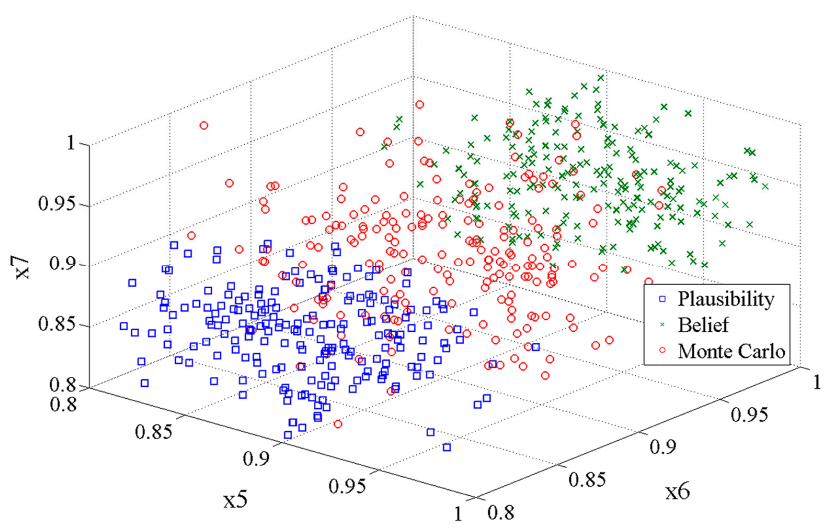

(a)

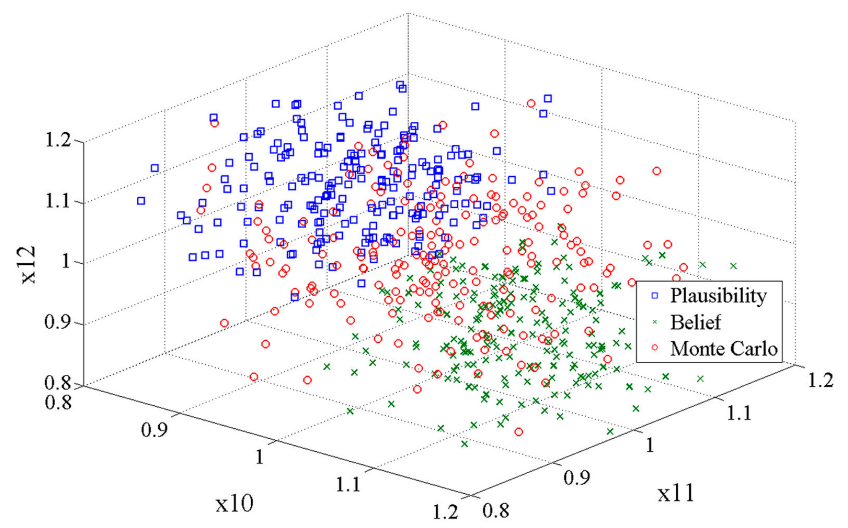

(b)

Figure 4. Cont . 


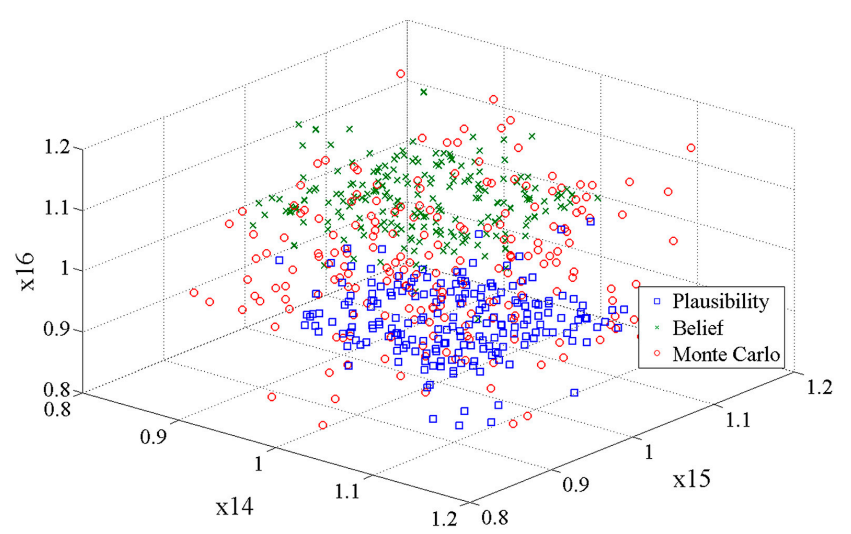

(c)

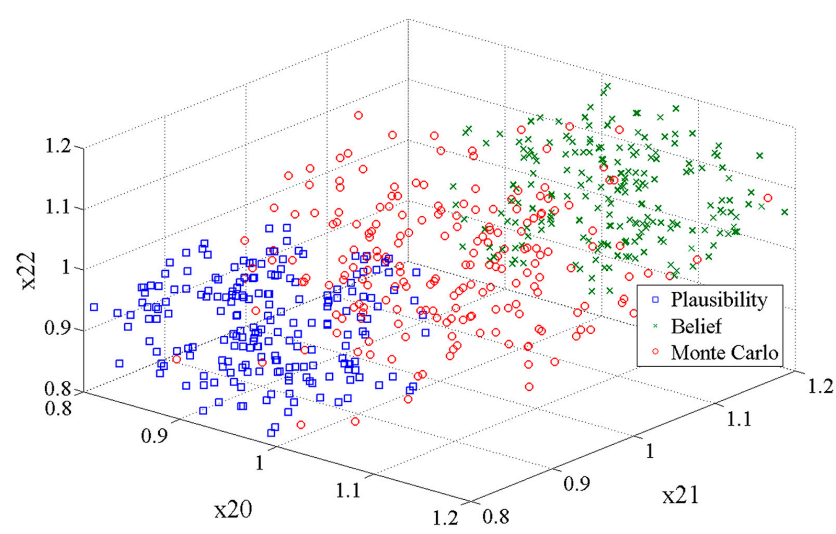

(d)

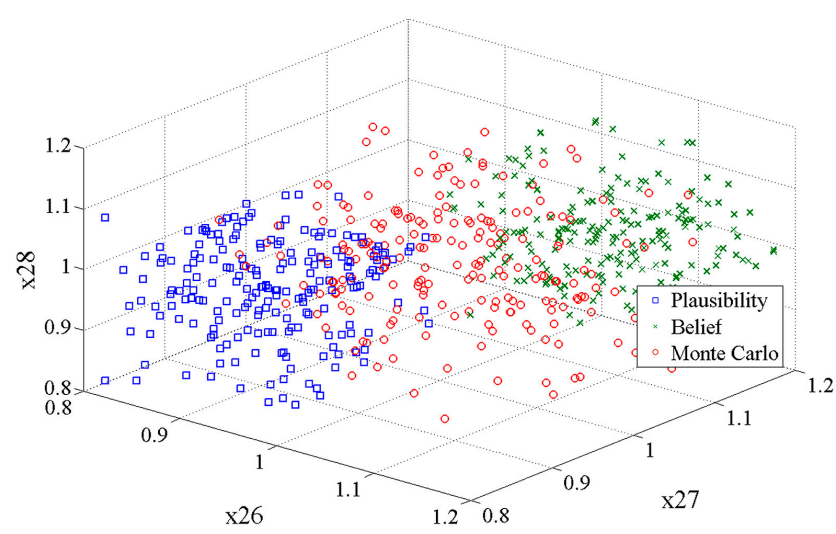

(e)

Figure 4. Sampling results using the Latin hypercube sampling (LHS) method. (a) Sampling results of thermal zone (x5: Fraction person per area, x6: Fraction internal gain for lights, x7: Fraction internal gain for equipment); (b) Sampling results of the heating, ventilation and air conditioning (HVAC) system (x10: Design water flow rate, x11: Design water inlet/outlet temperature ratio, x12: Design air flow ratio); (c) Sampling results of fan (x14: Fan efficiency ratio, x15: Pressure rise ratio, x16: Motor efficiency ratio); (d) Sampling results of pump (x20: Pump head ratio of chilled water, x21: Motor efficiency ratio of chilled water, x22: Pump head ratio of condenser); (e) Sampling results of plant (x26: Coefficient of performance (COP) for cooling, x27: COP of heating, x28: Design inlet temperature ratio). 
Table 3 and Figure 5 show the uncertainty results of the fuzzy MCS compared with those of the MCS. In the case of the fuzzy MCS, the uncertainty results were represented as a family of probability distributions with a range between plausibility and belief distribution. On the other hand, the results of the MCS are located between the plausibility and belief distribution.

The difference in distance between the plausibility and belief distribution is closely connected with a lack of definite physical or experimental knowledge. A large difference in the distance implies that the predicted outputs are strongly influenced by unknown inputs that have an epistemic nature. In addition, the plausibility and belief distribution denote optimistic and pessimistic outcomes, respectively [5,6]. If the building stakeholders (e.g., architect, owner, engineer, and occupants) have optimistic preferences about the model risks, the plausibility distribution should be used for risk-based decision support. Otherwise, the belief distribution should be used. In the results, the uncertainty results of the thermal zone showed that the epistemic uncertainties have a decisive effect on the heating/cooling load since a strong difference was shown in the distance between the plausibility and belief distribution.

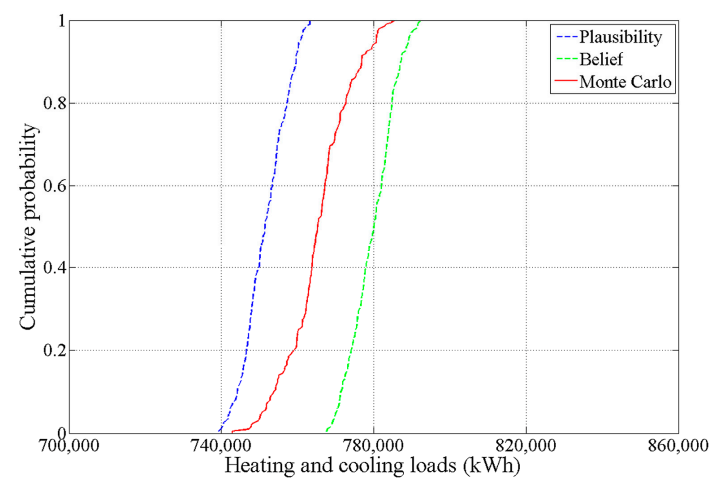

(a)

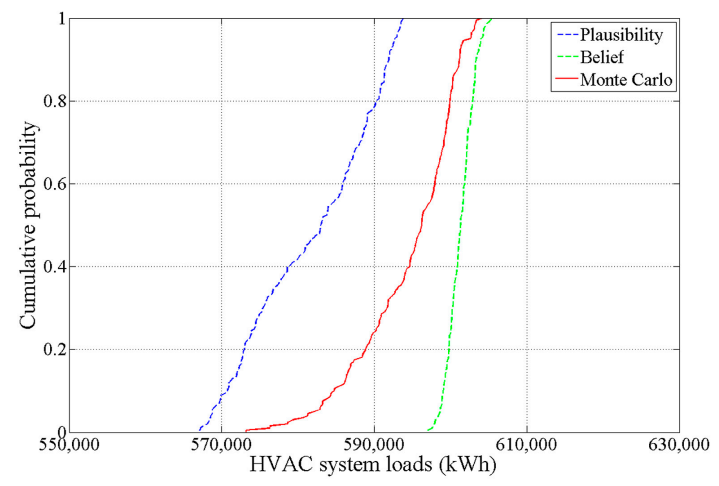

(b)

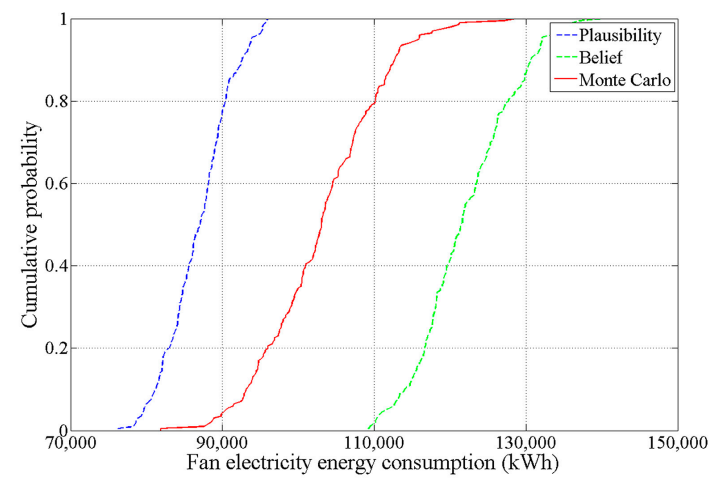

(c)

Figure 5. Cont. 


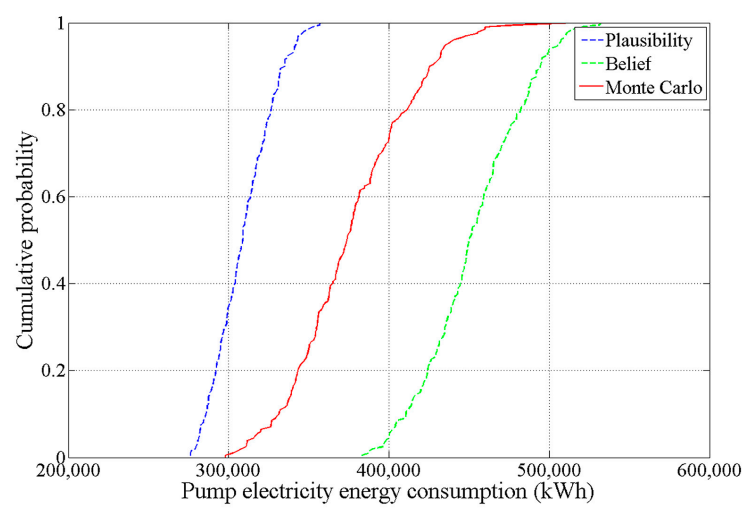

(d)

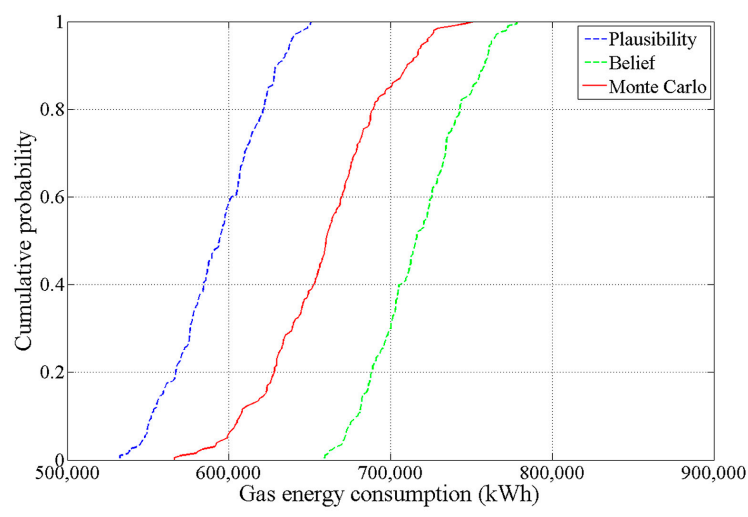

(e)

Figure 5. MCS vs. fuzzy MCS using cumulative probability. (a) Uncertainty results of thermal zone; (b) Uncertainty results of the HVAC system; (c) Uncertainty results of fan; (d) Uncertainty results of pump; (e) Uncertainty results of plant.

Table 3. Uncertainty results: Monte Carlo simulation (MCS) vs. fuzzy MCS.

\begin{tabular}{ccccccc}
\hline Systems & Functions & $\begin{array}{c}\text { Mean } \\
\mathbf{( k W h )}\end{array}$ & $\begin{array}{c}\text { Standard } \\
\text { Deviation } \mathbf{( k W h )}\end{array}$ & $\begin{array}{c}\text { Min } \\
\mathbf{( k W h )}\end{array}$ & $\begin{array}{c}\text { Max } \\
\mathbf{( k W h )}\end{array}$ & $\begin{array}{c}\text { Coefficient of Variation } \\
\text { (Dimensionless) }\end{array}$ \\
\hline \multirow{2}{*}{ Zone } & Belief & 779,778 & 5825 & 767,679 & 792,771 & 0.00747 \\
& Monte Carlo & 765,544 & 8397 & 742,917 & 785,540 & 0.01097 \\
& Plausibility & 751,651 & 5679 & 739,364 & 763,286 & 0.00756 \\
\hline \multirow{3}{*}{ HVAC } & Belief & 601,325 & 1697 & 597,029 & 605,535 & 0.00282 \\
& Monte Carlo & 594,505 & 6451 & 573,222 & 604,237 & 0.01085 \\
& Plausibility & 581,836 & 8052 & 567,116 & 593,879 & 0.01384 \\
\hline \multirow{3}{*}{ Fan } & Belief & 122,051 & 6346 & 109,277 & 140,152 & 0.05199 \\
& Monte Carlo & 103,184 & 7806 & 81,917 & 128,638 & 0.07565 \\
& Plausibility & 86,851 & 4263 & 76,277 & 96,126 & 0.04908 \\
\hline \multirow{3}{*}{ Pump } & Belief & 452,561 & 31,453 & 383,288 & 532,293 & 0.06950 \\
& Monte Carlo & 376,932 & 37,474 & 298,143 & 514,584 & 0.09942 \\
& Plausibility & 309,587 & 18,422 & 276,177 & 357,096 & 0.05951 \\
\hline \multirow{2}{*}{ Plant } & Belief & 716,927 & 28,764 & 659,183 & 778,085 & 0.04012 \\
& Monte Carlo & 659,598 & 37,264 & 566,242 & 752,066 & 0.05650 \\
& Plausibility & 593,222 & 28,599 & 532,686 & 650,750 & 0.04821 \\
\hline
\end{tabular}




\subsection{Global Sensitivity Results}

The sensitivity analysis quantifies the influence of unknown inputs on the outputs with probability distributions. The sensitivity analysis should lead to (1) ranking unknown inputs in order of importance; (2) identifying influential and non-influential inputs; (3) reducing the variance of the outputs, and (4) finding influential inputs and their subset in a given probability range. In this study, the standardized rank regression coefficient (SRRC) method for the global sensitivity analysis was used; the SRRC method uses a rank transformation and is suitable for a nonlinear model [18-20].

Table 4 shows the sensitivity results (sensitivity index and rank) for finding optimal design solutions among possible design variables. In the case of the thermal zones (x1-x9), lights ( $x 6)$ and equipment $(x 7)$ were chosen as influential design variables. In terms of heating/cooling load, the lights and equipment were more sensitive than the type $(x 1)$ and thickness $(x 2)$ of the insulation boards; the type (x3) and airtightness ( $x 4)$ of the glass; the number of occupants (x5); and the indoor set-point temperatures ( $x 8$ and $x 9$ ). In particular, the sensitivity result of the equipment was higher than that of lights because some light fixtures were replaced with high efficient LED lamps, while the equipment (PC, copy machine, TV, etc.) had not been replaced. The results showed that the ranks, except for the lights and equipment, should be changed according to the preferred distributions (plausibility or belief distribution).

Table 4. Global sensitivity results.

\begin{tabular}{|c|c|c|c|c|c|c|}
\hline \multirow{2}{*}{ No. } & \multicolumn{2}{|c|}{ Plausibility } & \multicolumn{2}{|c|}{ Belief } & \multicolumn{2}{|c|}{ Monte Carlo } \\
\hline & SI & Rank & SI & Rank & SI & Rank \\
\hline $\mathrm{x} 1$ & 0.008 & 6 & -0.004 & 8 & 0.039 & 3 \\
\hline$x 2$ & 0.006 & 7 & -0.006 & 6 & -0.015 & 6 \\
\hline$x 3$ & -0.021 & 3 & 0.0001 & 9 & -0.025 & 5 \\
\hline$x 4$ & 0.011 & 4 & 0.007 & 5 & 0.009 & 7 \\
\hline$x 5$ & 0.003 & 9 & 0.004 & 7 & -0.006 & 8 \\
\hline$x 6$ & 0.357 & 2 & 0.350 & 2 & 0.374 & 2 \\
\hline $\mathrm{x} 7$ & 0.951 & 1 & 0.946 & 1 & 0.948 & 1 \\
\hline$x 8$ & -0.004 & 8 & -0.008 & 4 & 0.035 & 4 \\
\hline x9 & -0.008 & 5 & -0.009 & 3 & 0.004 & 9 \\
\hline x10 & 0.168 & 2 & 0.664 & 1 & 0.264 & 2 \\
\hline x11 & -0.984 & 1 & -0.541 & 2 & -0.913 & 1 \\
\hline $\mathrm{x} 12$ & -0.113 & 3 & -0.445 & 3 & -0.177 & 3 \\
\hline$x 13$ & -0.003 & 4 & 0.025 & 4 & 0.040 & 4 \\
\hline x14 & -0.590 & 2 & -0.744 & 1 & -0.659 & 2 \\
\hline x15 & 0.748 & 1 & 0.606 & 2 & 0.659 & 1 \\
\hline x16 & -0.008 & 5 & 0.0001 & 6 & 0.008 & 6 \\
\hline x17 & -0.295 & 4 & -0.363 & 3 & -0.277 & 3 \\
\hline x18 & 0.347 & 3 & 0.283 & 4 & 0.268 & 4 \\
\hline x19 & -0.003 & 6 & 0.011 & 5 & 0.014 & 5 \\
\hline x20 & 0.023 & 5 & 0.042 & 5 & 0.015 & 6 \\
\hline$x 21$ & -0.004 & 6 & -0.032 & 6 & -0.025 & 5 \\
\hline$x 22$ & 0.935 & 1 & 0.595 & 2 & 0.659 & 2 \\
\hline$x 23$ & -0.395 & 2 & -0.803 & 1 & -0.699 & 1 \\
\hline$x 24$ & 0.087 & 3 & 0.069 & 4 & 0.067 & 3 \\
\hline$x 25$ & -0.031 & 4 & -0.083 & 3 & -0.066 & 4 \\
\hline$x 26$ & 0.360 & 2 & 0.364 & 2 & 0.440 & 2 \\
\hline$x 27$ & 0.942 & 1 & 0.942 & 1 & 0.919 & 1 \\
\hline$x 28$ & -0.021 & 4 & 0.010 & 4 & 0.004 & 3 \\
\hline$x 29$ & 0.012 & 3 & -0.020 & 3 & 0.002 & 4 \\
\hline
\end{tabular}

In the case of the HVAC system (x10-x13), the design water inlet/outlet temperature (x11) and water flow (x10) for cooling and heating were more sensitive than the design air inlet/outlet 
temperature (x13) and air flow (x12) due to the difference between the thermal capacities of the air and those of the water. In other words, it is more advantageous to change the design water inlet/outlet temperature and water flow than to change the design air inlet/outlet temperature and air flow for efficient heat exchange between the heating and cooling coils and the returned air. In the case of sensitivity results using the plausibility distribution, the design water inlet/outlet temperature was chosen as the first priority. If the belief distribution is used, the design water flow rate should be chosen. In other words, the first priority for the HVAC system should also be identified, depending on whether the preferences of the stakeholders are optimistic or pessimistic.

In the case of the fan (x14-x19), the efficiency (x14) and pressure rise (x15) of the supply fan were chosen as more influential design variables than those of the return fans. These design variables were selected because the supply fan has an additional pressure drop for heat exchange inside the air-conditioner (heating and cooling coils) and air filter. In the case of the pump (x20-x25), the pump head (x22) and the motor efficiency (x23) of the condenser pump (primary pump) were chosen as more influential design variables than those of the chilled water and hot water pump (secondary pump). It can be inferred that the pump electricity energy consumption needs to be reduced by improving the primary pump rather than the secondary pump. Finally, for the absorption chiller/heater of the plant (x26-x29), the COPs (x26-x27) for the cooling and heating were chosen as more influential design variables than the design inlet/outlet temperature (x28-x29). In addition, the COP for heating was selected as a more influential design variable than the COP for cooling. To reach an efficient design, improving the heating efficiency is the preferred approach. However, it should be noted that the sensitivity index or ranks for fan, pump, and plant should be changed depending on the preferred distributions.

In summary, the influential inputs in the given target building are determined as follows: (1) lights and equipment for the cooling and heating load; (2) design water inlet/outlet temperature and water flow for the HVAC system load; (3) fan efficiency and pressure rise of the supply fan for the fan energy electricity consumption; (4) pump head and motor efficiency of the condenser pump for the pump energy electricity consumption; and (5) COPs of the absorption chiller/heater for the gas energy consumption. However, it should be noted that different design variables could be selected according to the preferred distributions of the stakeholders.

\section{Conclusions}

This study presents a comparison between the fuzzy MCS and the MCS for uncertainty and global sensitivity analysis in a given building. A global sensitivity analysis using the meta-model-based uncertainty results was conducted for finding influential inputs among all possible design variables in the existing office building. The SRRC method, which can provide the sensitivity measures that enable the quantitative identification of influential and non-influential inputs, was chosen.

Comparing the fuzzy MCS with the MCS, this study showed that the fuzzy MCS provides decision makers with more meaningful and trustworthy information than the MCS, since the MCS-based uncertainty propagation has trouble in dealing with the epistemic uncertainties (i.e., reducible uncertainties). Such trouble is caused by all the unknown inputs that were assigned as single probability distributions depending on the subjective knowledge and experiences of the simulationists. If each single probability distribution is biased, then the uncertainty and sensitivity analysis should fail to fulfil its role for the risk-based design support management.

On the other hand, the fuzzy MCS, which is a joint propagation method (probability theory of MCS and possibility theory of fuzzy arithmetic), can reflect aleatory as well as epistemic uncertainties, and obtain a family of probability distributions including plausibility and belief distribution. As shown in the global sensitivity results (refer to Section 5.2), such a probabilistic framework using the fuzzy MCS should offer stakeholders more chances to identify influential inputs by considering the factors behind the risks in a given range of the family of the distributions. In terms of the risk-based design 
support management considering decision makers' preferences (optimistic or pessimistic), the fuzzy MCS performs better than the MCS. Future works will include the following:

- Bayesian calibration based on the fuzzy MCS: the fuzzy MCS will be used to estimate posterior distributions of unknown inputs in the BPS tools

- Stochastic multi-criteria design based on the fuzzy MCS: by coupling between uncertainty results propagated using the fuzzy MCS and optimization techniques (e.g., genetic algorithm, particle swarm optimization), the multi-criteria design problems will be treated under uncertainty

Acknowledgments: This work was supported by the National Research Foundation of Korea (NRF) grant funded by the Korea government (MSIP) (No. 2015R1C1A1A01052976).

Author Contributions: Young-Jin Kim presented the Monte Carlo simulation-based fuzzy arithmetic for uncertainty and global sensitivity analysis in this paper.

Conflicts of Interest: The author declares no conflict of interest.

\section{Abbreviations}

The following abbreviations are used in this manuscript:

$\begin{array}{ll}\text { MCS } & \text { Monte Carlo simulation } \\ \text { GP } & \text { Gaussian process } \\ \text { TFN } & \text { Triangular fuzzy number } \\ \text { LHS } & \text { Latin hypercube sampling } \\ \text { COP } & \text { Coefficient of performance } \\ \text { MAP } & \text { Maximum a posteriori } \\ \text { K-S } & \text { Kolmogorov-Smirnov } \\ \text { SD } & \text { Standard deviation } \\ \text { SRRC } & \text { Standardized rank regression coefficient } \\ \text { SI } & \text { Sensitivity index }\end{array}$

\section{References}

1. Smith, R.C. Uncertainty Quantification: Theory, Implementation, and Applications (Computational Science and Engineering); Society for Industrial and Applied Mathematics: Philadelphia, PA, USA, 2013.

2. Burhenne, S.; Tsvetkova, O.; Jacob, D.; Henze, G.P.; Wagner, A. Uncertainty quantification for combined building performance and cost-benefit analyses. Build. Environ. 2013, 62, 143-154. [CrossRef]

3. Almeida, R.M.S.F.; Ramos, N.M.M.; Manuel, S. Towards a methodology to include building energy simulation uncertainty in the Life Cycle Cost analysis of rehabilitation alternatives. J. Build. Eng. 2015, 2, 44-51. [CrossRef]

4. Cheng, Q.; Wang, S.; Yan, C. Robust optimal design of chilled water systems in buildings with quantified uncertainty and reliability for minimized life-cycle cost. Energy Build. 2016, 126, 159-169. [CrossRef]

5. Dubois, D.; Guyonnet, D. Risk-informed decision-making in the presence of epistemic uncertainty. Int. J. Gen. Syst. 2011, 40, 145-167. [CrossRef]

6. Clavreul, J.; Guyonnet, D.; Tonini, D.; Christensen, T. Stochastic and epistemic uncertainty propagation in LCA. Int. J. Life Cycle Assess. 2013, 18, 1393-1403. [CrossRef]

7. Rasmussen, C.E.; Williams, C.K.I. Gaussian Processes for Machine Learning; MIT Press: Cambridge, MA, USA, 2006; ISBN: 0-262-18253-X.

8. Kim, Y.J. Comparative study of surrogate models for uncertainty quantification of building energy model: Gaussian process emulator vs. polynomial chaos expansion. Energy Build. 2016, 133, 46-58. [CrossRef]

9. Kiureghian, A.D. Aleatory or epistemic? Does it matter? In Proceedings of the Special Workshop on Risk Acceptance and Risk Communication, Stanford, CA, USA, 20-27 March 2007.

10. IBPSA (International Building Performance Simulation Association). Proceedings of the IBPSA (International Building Performance Simulation Association) Conference 2015, Hyderabad, India, 7-9 December 2015; Mathur, J., Garg, V., Eds.; IBPSA: Toronto, ON, Canada, 2015.

11. Zadeh, L. Fuzzy sets. Inf. Control 1965, 8, 338-353. [CrossRef] 
12. Hanss, M.; Turrin, S. A fuzzy-based approach to comprehensive modelling and analysis of systems with epistemic uncertainties. Struct. Saf. 2010, 32, 433-441. [CrossRef]

13. Mauris, G.; Lasserre, V.; Foulloy, L. A fuzzy approach for the expression of uncertainty in measurement. Measurement 2001, 29, 165-177. [CrossRef]

14. Chutia, R.; Mahanta, S.; Datta, D. Non-parametric sensitivity and uncertainty analysis of atmospheric dispersion. Ann. Fuzzy Math. Inform. 2013, 5, 213-228.

15. Reza, B.; Sadiq, R.; Hewage, K. A fuzzy-based approach for characterization of uncertainties in emergy synthesis: An example of paved road system. J. Clean. Prod. 2013, 59, 99-110. [CrossRef]

16. Kim, Y.J.; Park, C.S. Stepwise deterministic and stochastic calibration of an energy simulation model for an existing building. Energy Build. 2016, 133, 455-468. [CrossRef]

17. SAREK (Society of Air-Conditioning and Refrigerating Engineers of Korea). Equipment Engineering Handbook; Society of Air-Conditioning and Refrigerating Engineers of Korea: Seoul, Korea, 2004.

18. Saltelli, A.; Tarantola, S.; Campolongo, F.; Ratto, M. Sensitivity Analysis in Practice; Wiley \& Sons Ltd.: Chichester, UK, 2004.

19. Saltelli, A.; Ratto, M.; Andres, T.; Campolongo, F.; Cariboni, J.; Gatelli, D.; Saisana, M.; Tarantola, S. Global Sensitivity Analysis; John Wiley \& Sons Ltd.: Chichester, UK, 2008.

20. Tian, W. A review of sensitivity analysis methods in building energy analysis. Renew. Sustain. Energy Rev. 2013, 20, 411-419. [CrossRef]

(C) 2017 by the author. Licensee MDPI, Basel, Switzerland. This article is an open access article distributed under the terms and conditions of the Creative Commons Attribution (CC BY) license (http://creativecommons.org/licenses/by/4.0/). 